\title{
Fibroblast to myofibroblast transition is enhanced in asthma- derived fibroblasts in comparison to fibroblasts derived from non-asthmatic patients in 3D in vitro cultures due to Smad2/3 signalling*
}

\author{
Dawid Wnuk\#, Sławomir Lasota\#, Milena Paw, Zbigniew Madeja and Marta Michalik四 \\ Department of Cell Biology, Faculty of Biochemistry, Biophysics and Biotechnology, Jagiellonian University, Kraków, Poland
}

The basic hallmarks of bronchial asthma, one of the most common chronic diseases occurring in the world, are chronic inflammation, remodelling of the bronchial wall and its hyperresponsiveness to environmental stimuli. It was found that the fibroblast to myofibroblast transition (FMT), a key phenomenon in subepithelial fibrosis of the bronchial wall, was crucial for the development of asthma. Our previous studies showed that HBFs derived from asthmatic patients and cultured in vitro display some inherent features which facilitate their TGF- $\beta$ induced FMT. Although usefulness of standard '2D' cultures is invaluable, they have many limitations. As HBFs interact with extracellular matrix proteins in the connective tissue, which can affect the FMT potential, we have decided to expand our ' $2 \mathrm{D}$ ' model to in vitro cell cultures in 3D using collagen gels. Our results show that $1.5 \mathrm{mg} /$ $\mathrm{ml}$ concentration of collagen is suitable for HBFs growth, motility, and phenotypic shifts. Moreover, we demonstrate that in the TGF- $\beta_{1}$-activated HBF populations derived from asthmatics, the expression of fibrosis-related genes (ACTA2, TAGLN, SERPINE1, COL1A1, FN1 and CCN2) was significantly increased in comparison to the nonasthmatic ones. We also confirmed that it is related to the TGF- $\beta / S m a d 2 / 3$ profibrotic pathway intensification. In summary, the results of our study undoubtedly demonstrate that HBFs from asthmatics have unique intrinsic features which predispose them to increased FMT under the influence of TGF- $\beta_{1}$, regardless of the culture conditions.

Key words: $3 \mathrm{D}$ cell cultures, TGF- $\beta$, fibroblast to myofibroblast transition, subepithelial fibrosis, asthma remodelling

Received: 25 April, 2020; revised: 12 August, 2020; accepted: 15 August, 2020; available on-line: 27 November, 2020

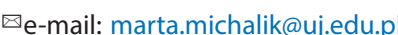

"contributed equally

*A preliminary report on this subject was presented at the XLVII Winter School of the Faculty of Biochemistry, Biophysics and Biotechnology of the Jagiellonian University "Molecules, Pathways, and Games", February 8-12, 2020, Zakopane, Poland.

Acknowledgements of Financial Support: This study was supported by the Polish National Science Centre (2015/17/B/NZ3/02248) grant to MM. DW obtained financial resources from the Polish $\mathrm{Na}$ tional Science Centre as part of the doctoral scholarship ETIUDA (2019/32/T/NZ3/00405)

Abbreviations: $a-S M A$, $a$-smooth muscle actin isoform; ACTA2, a-SMA encoding gene; AS, patients with asthma (asthmatics); $B S A$, bovine serum albumin; CCN2, connective tissue growth factor (CTGF) encoding gene; COL1A1, collagen 1A1 encoding gene; DIC, differential interference contrast; DMEM HG, Dulbecco's Modified Essential Medium High Glucose; FBS, foetal bovine serum; FEV, forced expiratory volume; FMT, fibroblast-to-myofibroblast transition; FN1, fibronectin 1 encoding gene; IMC, integrated modulation contrast; HBFs, human bronchial fibroblasts; NA, patients without asthma (non-asthmatics); SERPINE1, plasminogen activator inhibitor 1 (PAI-1) encoding gene; PBS, phosphate-buffered saline; TAGLN, transgelin encoding gene; TGF- $\beta_{1}$, transforming growth factor $\beta$

\section{INTRODUCTION}

Bronchial asthma, which affects 300 million people in the world, is one of the most common chronic diseases occurring in the world and is characterised by variable respiratory symptoms (including changes in the type, quantity, and nature of airway wall components, named airway remodelling) and variable airflow limitation. Currently used asthma treatment is symptomatic, mostly based on the relief of inflammation in the respiratory tract and alleviation of the effects of bronchial obstruction. Since these therapies have a negligible effect on bronchial remodelling, many researchers try to elaborate on new therapeutic approaches that directly target the pro-fibrotic processes, including the subepithelial fibrosis in asthma, and using both - the experimental animal models and in vitro cell cultures. We are also constantly looking for ways to stop progressive bronchial remodelling by studying the mechanisms of fibroblast to myofibroblast transition (FMT), a key phenomenon in the subepithelial fibrosis of the bronchial wall in asthmatic patients (Michalik et al., 2018). For several years we have been using an in vitro model of human bronchial fibroblasts (HBFs) obtained from bronchoscopy sections from patients with asthma (AS) and from patients in whom asthma was excluded (NA). Numerous experiments carried out with our in vitro model indicate inherent features of HBFs AS favouring their FMT in '2D' cultures (Michalik et al., 2009, 2011, 2012; Wójcik et al., 2012; Sarna et al., 2015; Paw et al., 2017). Nowadays, two-dimensional cell cultures are the gold standard for many different applications in cellular and medical biology. Although their usefulness is invaluable, they have many limitations. In fact, cell growth in a monolayer on the plastic surface (even coating of culture dishes with extracellular matrix proteins or synthetic polymers) does not mirror the complexity of the in vivo cell microenvironment architecture. In recent years, a growing branch of in vitro research is studying 3D systems which more closely reflect the in vivo conditions (Artym \& Matsumoto, 2010; Kural \& Billiar, 2013; Kofron \& Mende, 2017; Di Modugno et al., 2019). Though many studies were focused on 3D experimental collagen tissue-models suitable for investigation of normal and pathological fibroblast functions (Brown, 2013; Petrie \& Yamada, 2015; Kanta, 2015), to the best of our knowledge there 
is no published data on the HBFs derived from asthmatics cultured under 3D conditions. As HBFs interact with extracellular matrix proteins in the connective tissue, which can affect the FMT potential, we have decided to expand our ' $2 \mathrm{D}$ ' model to include the in vitro cell cultures in 3D using commercially available collagen gels. The aim of our study was to estimate the effect of the cell microenvironment on the susceptibility of AS and NA HBFs to the transforming growth factor- $\beta_{1}$ (TGF$\beta_{1}$ )-induced FMT with special emphasis on the Smaddependent TGF- $\beta_{1}$ signalling in 3D in vitro cultures, and compare these results with the ones previously obtained with standard '2D' cultures.

\section{MATERIALS AND METHODS}

Isolation and culture of HBFs. Primary HBFs were isolated from bronchial biopsies as described previously (Michalik et al., 2009; Paw et al., 2018). Fibroblasts were derived from two groups: the first group - AS (asthmatics) consisted of 6 patients with asthma severity 3-4 according to the Global Initiative for Asthma Classification (group AS: 3 males, 3 females; average age: 46.67 \pm 16.73 years; mean duration of asthma: $11.67 \pm 9.89$ years; mean FEV1\%: 63.07 \pm 17.31 predicted; average age at asthma diagnosis: $34.83 \pm 19.16$ years; BMI: $\left.26.7 \pm 4.85 \mathrm{~kg} / \mathrm{m}^{2}\right)$. The second group - NA (non-asthmatics) consisted of 6 patients in whom clinical diagnostics ruled out any serious airway pathology, including asthma, any other fibrotic lung diseases and cancer (group NA: 3 males and 3 females; average age: $55.75 \pm 12.84$ years). All participants have never smoked. Means of anamnesis and additional tests: imaging, lung function tests, spirometry, histopathological examination of bronchial samples, allergy tests, and microbiological tests excluded other diseases causing cough. COPD was excluded by the history and results of spirometry. They were finally diagnosed with post-infectious or idiopathic cough. All patients were treated at the Department of Medicine of the Jagiellonian University Medical College and remained in a stable clinical condition. This study was approved by the University's Ethics Committee (Decision No. 122.6120.16.2016) and all patients provided informed consent to participate in this study. Cells were cultured in Dulbecco's Modified Essential Medium with high glucose (DMEM HG), with $10 \%$ foetal bovine serum (FBS) and a penicillin/streptomycin cocktail (Paw et al., 2018), at $37^{\circ} \mathrm{C}$ in a humidified atmosphere with $5 \% \mathrm{CO}_{2}$ to $80-85 \%$ confluence and used for experiments between the 5 th and 15 th passages.

Culture of $\mathrm{HBF}$ under $3 \mathrm{D}$ conditions. A collagen matrix, used as a substrate for the $3 \mathrm{D}$ in vitro culture, was prepared from bovine collagen I (ThermoFisher Scientific) according to the protocol provided by manufacturer, based on the cell culture medium $-5 \times$ concentrated DMEM HG (Sigma Aldrich) prepared from powder and filtered. Collagen concentration, ranging from 0.5 to 3.0 $\mathrm{mg} / \mathrm{ml}$ was prepared depending on the experiment. 3D in vitro culture was prepared according to the protocol by (Artym \& Matsumoto, 2010), with minor modifications.

A commercially available glass bottom chamber (Eppendorf Cell Imaging Coverglass ${ }^{\circledR}(8$-well)) was initially filled with a thin layer of cell-free collagen gel (Fig. 1). After its polymerization (about 30 mins later), another layer of collagen (of the same density) that was mixed with cells (AS or NA HBFs) at a proper quantity (5$15 \times 10^{3}$ cells per well) was poured gently onto the bottom one. Finally, after further 30 mins, each well was filled with a cell culture medium without serum (DMEM

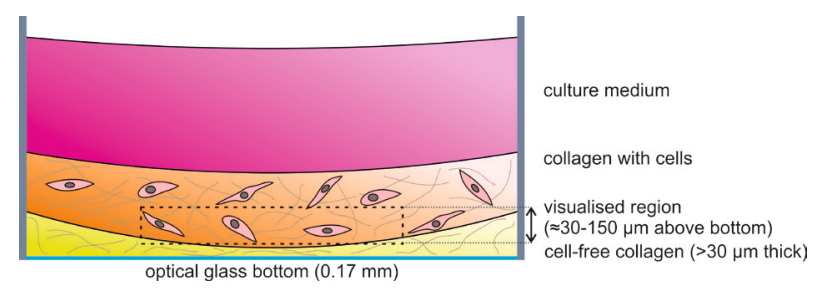

Figure 1. Scheme presenting general setting of 3D in vitro culture based on collagen matrix.

Cross sectional side view of a single well with prepared $3 \mathrm{D}$ in vitro culture of HBFs. Particular objects on the scheme are not drawn to scale.

HG supplemented with $0.1 \%$ BSA, Sigma Aldrich). Such strategy prevented cells from falling down onto a rigid glass bottom, and simultaneously providing homogenous collagen matrix for cell growth under 3D conditions. After $48 \mathrm{hrs}$, cells were stimulated with TGF- $\beta_{1}(5 \mathrm{ng} /$ $\mathrm{ml}, \mathrm{BD}$ Bioscience; dissolved in a solution of $1 \mathrm{mg} / \mathrm{ml}$ BSA/PBS) for the required period of time.

Cell imaging. Various systems based on inverted microscopes were used. Low magnification images of $3 \mathrm{D}$ culture under transmitted light were acquired with Leica DM IL LED equipped with 10-20× objectives, integrated modulation contrast (IMC) method and CMOS camera (Motic). High magnification and fluorescence imaging were performed with Leica DMI6000B fully motorized microscope, equipped with $63 \times$ objective, and Leica DFC360FX CCD camera (all Leica Wetzlar). General image processing was performed with Fiji ImageJ (Schindelin et al., 2012).

Immunofluorescence studies. In order to verify nuclear translocation of $\mathrm{p}-\mathrm{Smad} 2 / 3$, serum-starved cells $\left(1 \times 10^{4}\right.$ per well $)$ growing in $3 \mathrm{D}$ culture were stimulated for 1 hour with TGF- $\beta_{1}(5 \mathrm{ng} / \mathrm{ml})$, then fixed with $3.7 \%$ formaldehyde, permeabilized with a saponin solution (Paw et al., 2018), and blocked with 1\% BSA (all in PBS). Mouse monoclonal anti-p-Smad2/3 antibody conjugated with AlexaFluor-647 (BD Biosciences; 562696) was used overnight for direct immunodetection. Cell nuclei were additionally stained with Hoechst 33258 (Thermo Fisher) as a reference. Images were acquired with Leica DMI6000B microscope as described before by using both - fluorescence microscopy and differential interference contrast (DIC). Only cells localized between 50-150 $\mu \mathrm{m}$ above a rigid substratum were taken into consideration. Quantitative analysis of the obtained images was conducted with the LAS X software (Leica). Cell nuclei were manually outlined based on the nuclear stain signal. Mean fluorescence intensity was taken (for both Hoechst and A647 channels) and the background was subtracted, and then the nuclear $\mathrm{p}-\mathrm{Smad} 2 / 3$ signal was divided by the nuclear stain, and such a ratio was averaged for at least 30 cell nuclei of one HBFs population. Finally, change in the TGF- $\beta_{1}$ stimulated $\mathrm{HBF}$ relative to control conditions was compared between the examined cell types.

Quantitative real-time PCR. HBFs $\left(1.5 \times 10^{4}\right.$ per well, 4 wells for condition) growing in $3 \mathrm{D}$ culture were stimulated for 48 hours with TGF- $\beta_{1}(5 \mathrm{ng} / \mathrm{ml})$. After collecting the samples from HBFs ( $n=12: 6$ AS, 6 $\mathrm{NA}$ ) the isolation of $\mathrm{mRNA}$ was performed using the GeneMATRIX Universal RNA/miRNA Purification Kit (EURx, Gdańsk, Poland), according to the manufacturer's protocol. Concentration of the isolated mRNA was measured with a NanoDrop spectrophotometer (Implen) at OD260/280 nm. For cDNA synthesis with the use of 
Table 1. Primer sets used for qRT-PCR

\begin{tabular}{|c|c|c|}
\hline \multirow{2}{*}{ Name of human gene } & \multicolumn{2}{|l|}{ Gene sequence $5^{\prime}-3^{\prime}$} \\
\hline & Forward & Reverse \\
\hline ACTA2 & CTGTTCCAGCCATCCTTCAT & CCGTGATCTCCTTCTGCATT \\
\hline $\mathrm{CCN} 2$ & CCAACCGCAAGATCGGCGTG & GTCTTCCAGTCGGTAAGCCGCG \\
\hline COL1A1 & CTTTGCATTCATCTCTCAAACTTAGTITT & CCCCGCATGGGTCTTCA \\
\hline FN1 & TGTGGTTGCCTTGCACGAT & GCTTGTGGGTGTGACCTGAGT \\
\hline GAPDH & GAAGGTGAAGGTCGGAGT & GAAGATGGTGATGGGATTTC \\
\hline SERPINE1 & CGCCAGAGCAGGACGAA & TTGGCAAATGCTTTCGCTC \\
\hline TAGLN & CGTGGAGATCCCAACTGGTT & AAGGCCAATGACATGCTTTCC \\
\hline
\end{tabular}

C1000 Touch Thermal Cycler (Bio-Rad), 80 nanograms of the isolated mRNA and the NG dART RT-PCR Kit (EURx) were used. Expression of selected human genes ( ACTA2, CCN2, COL1A1, FN1, SERPINE1, TAGLN) was measured with SYBR Green PCR Master Mix (Applied Biosystems) and specific primer sets (described in Table 1; all from Genomed, Warszawa, Poland), using the 7500 Fast System (Applied Biosystems). Relative amounts of genes were estimated using the quantification threshold value recalculated against GAPDH transcripts by the $\Delta C \mathrm{C}$ method $[\Delta \mathrm{CT}$ refers to $\mathrm{CT}$ (tested gene $)-C T(G A P D H)]$ and were presented in relations to the control as a $2^{-\Delta \Delta C t}$ mean value.

Collagen lattice contraction assay. Cells cultured in the $3 \mathrm{D}$ collagen matrix at the density of $1.5 \times 10^{4}$ per well were starved for 48 hours and stimulated with TGF- $\beta_{1}$ for another 48 hours. Images were acquired with the stereoscopic microscope Leica S9i and inverted microscope Leica DMI8 equipped with Leica 170 HD CMOS camera and IMC method (all Leica Wetzlar).

Statistical analysis. Statistical significance was determined using the non-parametric Mann-Whitney test or Student's t-test (for p-Smad translocation) (a comparison between groups of HBFs NA and HBFs AS) with $* p<0.05 \%$ or $* * p<0.01 \%$ to indicate significant differences. Each parameter was calculated as the mean $( \pm$ S.E.M).

\section{RESULTS}

\section{Collagen concentration of $1.5 \mathrm{mg} / \mathrm{ml}$ is the best for 3D in vitro cultures of HBFs}

The morphology of fibroblasts growing under 3D conditions is in stark contrast to the one known from in vitro '2D' culture on rigid flat surfaces. Furthermore, it can strikingly vary depending on the characteristics of the exploited matrix, such as its density and stiffness. In case of collagen matrices, these parameters are modified by setting a proper collagen concentration. In order to prepare the collagen matrix providing optimal conditions for the HBFs growth, we performed screening of various collagen concentrations, ranging from 0.5 to $3 \mathrm{mg} /$ $\mathrm{ml}$. Cells were embedded in the collagen gel as described above. Exemplary images of cell morphology are pre- sented in Fig. 2A. Cells growing for 5 days in the collagen gel at a concentration between 1.5 and $2.5 \mathrm{mg} / \mathrm{ml}$ were well spread and stretched on collagen bundles that were clearly visible (Fig. 2A). Moreover, use of $1.5 \mathrm{mg} /$ $\mathrm{ml}$ concentration resulted in the lowest heterogeneity of cell morphology across the population. The healthy status of cells under these conditions was also confirmed by time-lapse imaging which showed that cells remain motile, mostly protruding in all directions, but visible translocation of HBFs was observed as well (Supplementary Movie 1 at https://ojs.ptbioch.edu.pl/index.php/abp/). Remaining concentrations led to cell contraction, either because of insufficient amount of adhesion sites (0.5-1.0 $\mathrm{mg} / \mathrm{ml}$ ), or oppositely, excessive confinement $(3.0 \mathrm{mg} /$ $\mathrm{ml})$. Based on the obtained results, all subsequent experiments were conducted at the collagen concentration of $1.5 \mathrm{mg} / \mathrm{ml}$.

TGF- $\beta_{1}$ treatment does not imply striking morphological changes of HBFs cultured in 3D

Subsequently, we verified the influence of TGF- $\beta_{1}$ stimulation on the morphology of cells growing under conditions selected previously (collagen gel of $1.5 \mathrm{mg}$ / $\mathrm{ml})$. Our in vitro experiments ran under '2D' conditions, where a rigid material such as glass, polystyrene or alike served as a substratum for cell growth, showed a striking fibroblast to myofibroblast transition after a few days (typically 4-7 days) of stimulation with TGF- $\beta_{1}$ $(5 \mathrm{ng} / \mathrm{ml})$. Such myofibroblasts were significantly more spread and consequently bigger than non-stimulated fibroblasts. What is noteworthy, this phenomenon was far more pronounced in the case of AS HBFs than NA HBFs (Michalik et al., 2009, 2011, 2012). Based on it, we expected a differential morphology of both of these types of $\mathrm{HBF}$ growing under 3D conditions, especially after TGF- $\beta_{1}$ stimulation. The conducted research did not show any visible differences between morphology of HBFs derived from both compared groups (AS and NA). Moreover, the TGF- $\beta_{1}$ stimulation did not cause any significant change in morphology of both, the NA and AS HBFs. Representative cells (presented in Fig. 2B) clearly reflect distribution of morphology among the examined populations. Under each condition there were multiple spindle-shaped cells, as well as some slightly more branched or spatially stretched cells on collagen bundles. Despite spatial arrangement of cells in 3D 
A

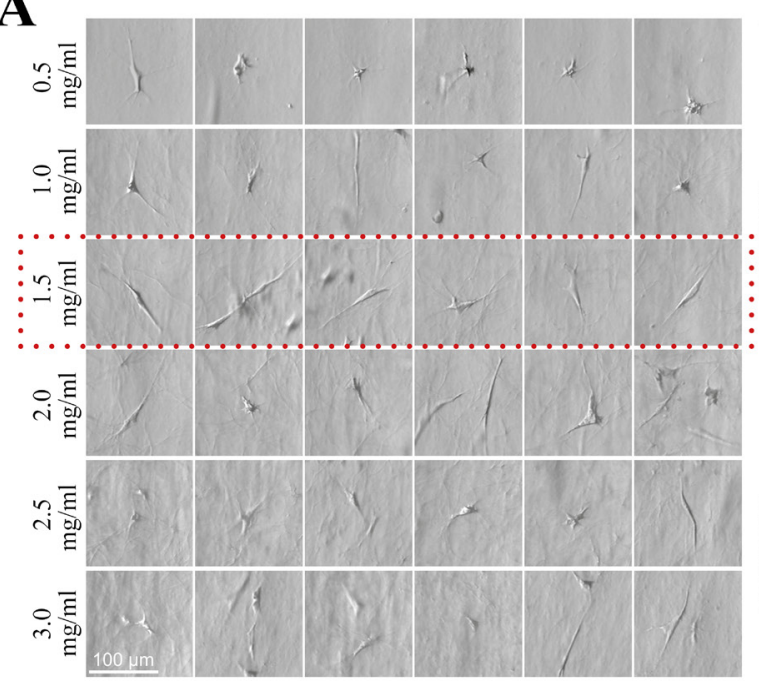

B

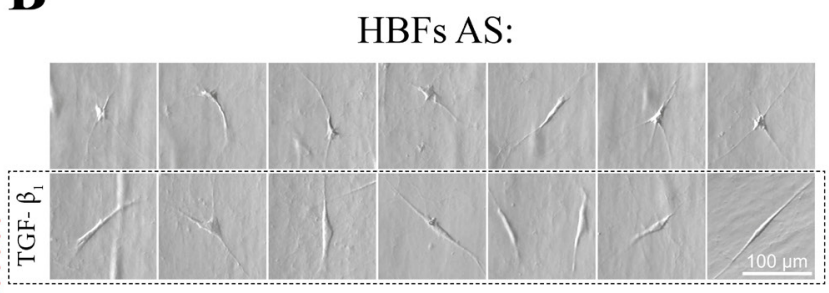

HBFs NA:

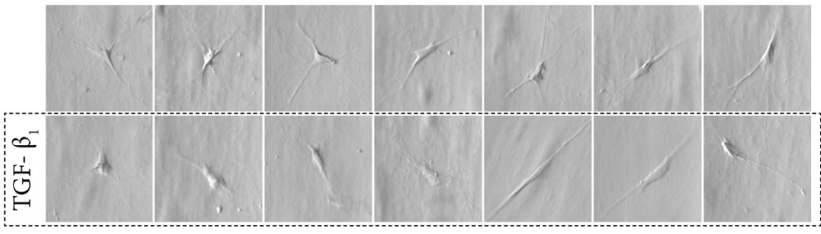

Figure 2. The morphology of HBFs growing under 3D conditions.

(A) HBFs AS embedded in collagen matrix of different concentrations $(0.5-3.0 \mathrm{mg} / \mathrm{ml})$. Images of representative cells captured at optimal focal plane (distant from the bottom to varying degrees). Images were captured after 5 days of culture with Leica IL LED using 10X objective and IMC. (B) TGF- $\beta$ treatment does not imply striking morphological changes of HBFs irrespective of their origin (either AS or NA). Representative images showing exemplary (randomly selected) HBFs from AS and NA patients growing in serum-free medium in the absence (control conditions) or presence of TGF- $\beta_{1}$. Cells were embedded in collagen matrix of $1.5 \mathrm{mg} / \mathrm{ml}$, starved for 48 hrs and treated with TGF- $\beta_{1}(5 \mathrm{ng} / \mathrm{ml})$ for another 6 days. Images were captured as previously described.

lattice, the top view of cells can be compared and it can be described as similar between both conditions, indicating a similar abundance of cell protrusions extended under all of these conditions.

\section{Potential to FMT is intensified in 3D in vitro cultured HBFs from asthmatics}

To compare the FMT efficiency of 3D cultured HBFs from AS and NA, we used a widely applied gel contraction assay (Matsumoto et al., 2007; Balestrini et al., 2012; Kollmannsberger et al., 2018). Bronchial fibroblasts derived from asthmatics shrink the gel much more efficiently than their non-asthmatic counterparts. What is more, the TGF- $\beta_{1}$ treatment strongly intensified this effect in HBFs AS (Fig. 3A). Additionally, microscopic observations confirmed that HBFs from AS thickened the collagen fibres, which may indicate a strong FMT after the TGF- $\beta_{1}$ treatment (Fig. 3B).

To confirm stronger FMT in $\mathrm{HBF}$ s $\mathrm{AS}$, we have analysed key genes related to FMT in our 3D model. The comparison of gene analysis between HBFs AS and NA grown in 3D cultures did not differ in the content of the FMT-related key genes under control conditions (Fig. 4). However, stimulation of HBFs AS and NA by TGF- $\beta_{1}$ caused clear differences between gene expression in the examined groups, similarly as under '2D' conditions (Paw et al., 2017). We observed that the widely recognized FMT gene markers, such as ACTA2 and TAGLN (known also as Sm22), one of the fibrogenesis markers (SERPINE1)(Omori et al., 2016), key extracellular matrix protein genes (COL1A1, FN1), as well as the CTGF coding gene (CCN2) (a cytokine significantly stimulating FMT) (Wójcik et al., 2012; Wójcik-Pszczoła et al., 2018), were much more highly expressed in HBFs AS than in NA after TGF- $\beta_{1}$ treatment (Fig. 4).

TGF- $\beta_{1} / \mathrm{Smad} 2 / 3$ signalling pathway is significantly more prominent in the case of $3 \mathrm{D}$ in vitro cultured HBFs derived from asthmatics

It was shown in our previous studies regarding ' $2 \mathrm{D}$ ' conditions, that the canonical TGF- $\beta_{1} / \mathrm{Smad} 2 / 3$ signal-
A

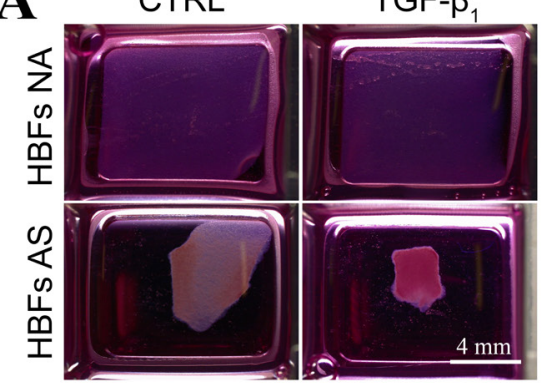

B

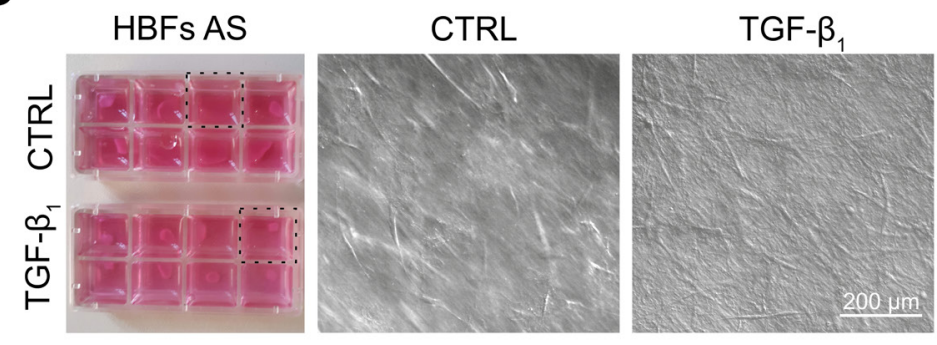

Figure 3. HBF AS shrink the collagen gel much more efficiently than their NA counterparts.

Cells were cultivated $48 \mathrm{~h}$ in a collagen gel $(1.5 \mathrm{mg} / \mathrm{ml})$. (A) Gel contraction assay by HBFs without (CTRL) and with TGF- $\beta_{1}$ ( 5 ng/ml). Comparison of HBFs AS vs NA. (B) Microscopic images of cells embedded in a relaxed and fully contracted collagen matrix (marked with a dashed frame on macroscopic image) prove that HBFs AS maintain well extended fibroblastic morphology despite collagen matrix contraction. 

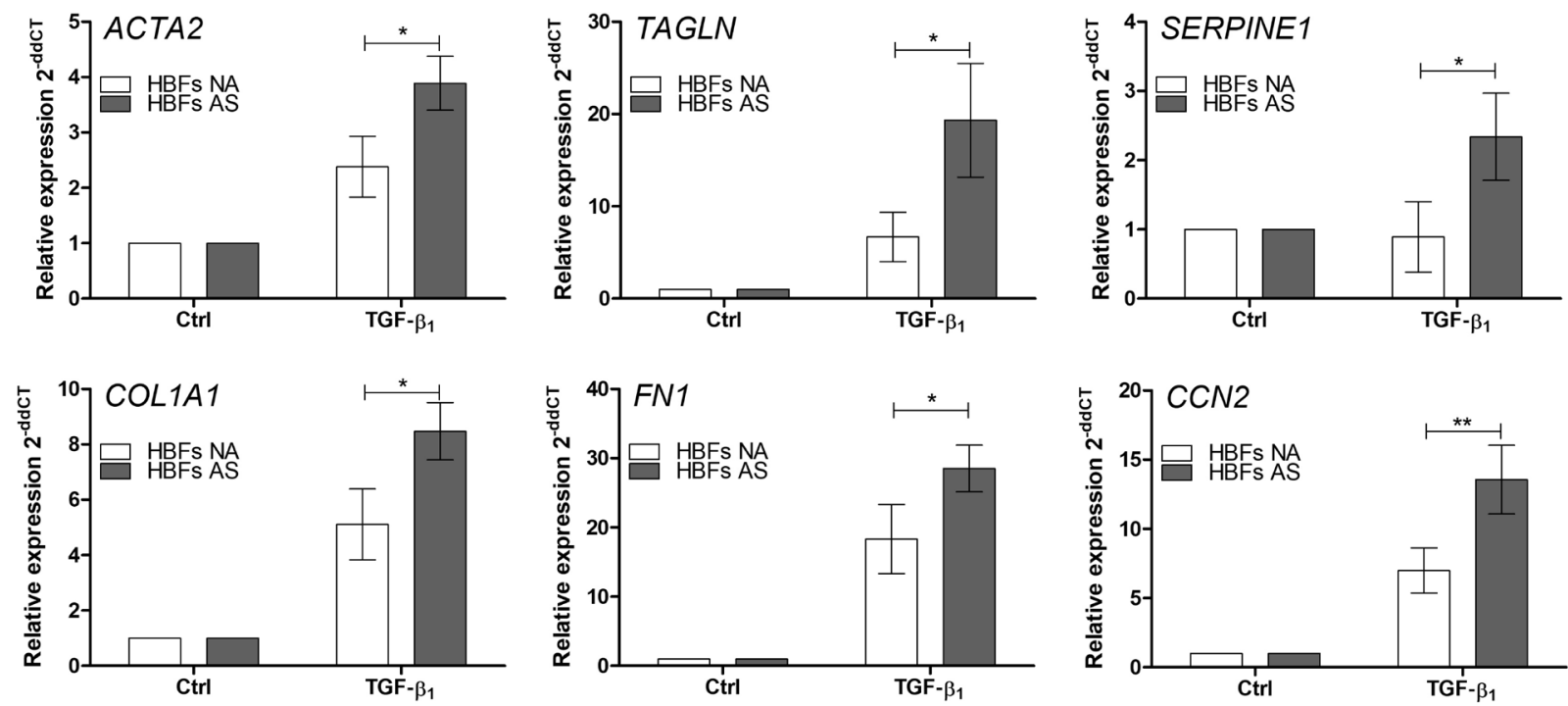

Figure 4. Relative expression of pro-fibrotic genes:

ACTA2 (a-SMA), TAGLN (transgelin; smooth muscle protein 22-alpha), SERPINE1 (plasminogen activator inhibitor-1 - PAI-1), COL1A1 (collagen 1A1), FN1 (fibronectin 1), CCN2 (CTGF). Cells (AS: $n=6 ; N A: n=6)$ were cultivated as described above (48 h collagen gel of $1.5 \mathrm{mg} /$ $\mathrm{ml}$ ) and mRNA was isolated, measured and RT-qPCR analyses of gene expression were performed. The relative relative amounts of genes were presented as a $2^{-\Delta \Delta c t}$ mean value. ${ }^{*} p<0.05 ;{ }^{* *} p<0.01$.

ling pathway was crucial for FMT (Michalik et al., 2013; Wójcik-Pszczoła et al., 2016; Wnuk et al., 2020). Since we observed an enhanced TGF- $\beta_{1}$-induced expression of profibrotic genes in HBFs derived from asthmatic patients when compared to non-asthmatic donors, we further focused on analysis of nuclear localisation of p-Smad2/3 between HBFs derived from both studied groups, in the developed 3D model. Results of the experiments carried out after 1 hour of TGF- $\beta_{1}$ stimulation of AS and NA HBF populations are summarized in Fig. 5.

These results (Fig. 5) clearly show that AS HBFs embedded in the $3 \mathrm{D}$ collagen matrix display signal transduction based on Smad2/3 phosphorylation after stimulation with TGF- $\beta_{1}$, which cannot be said about HBFs derived from non-asthmatic patients. Despite the observed heterogeneity of particular AS $\mathrm{HBF}$ response, the registered difference is statistically significant.

\section{DISCUSSION}

The phenotypic transition of fibroblasts to myofibroblasts is a key process during subepithelial fibrosis in bronchial wall remodelling in asthma. Many research groups have analysed its background, mechanisms, and participation of myofibroblasts in airway remodelling in asthma and in fibrotic processes in other organs (such as fibrosis of the kidney, liver or skin) (Gabbiani, 2003; Meran \& Steadman, 2011; Sarrazy et al., 2011). It is well documented by in vitro studies that FMT requires a combination of humoral and mechanical factors, as well as certain extracellular matrix proteins (Westergren-Thorsson et al., 2010; Michalik et al., 2018). On the other hand, our previous studies have shown that some (probably genetically or epigenetically acquired) inherent features of $\mathrm{HBFs}$ derived from asthmatic patients can also play a significant role in the expansion and enhanced progression of FMT in the asthmatic bronchial wall (Michalik
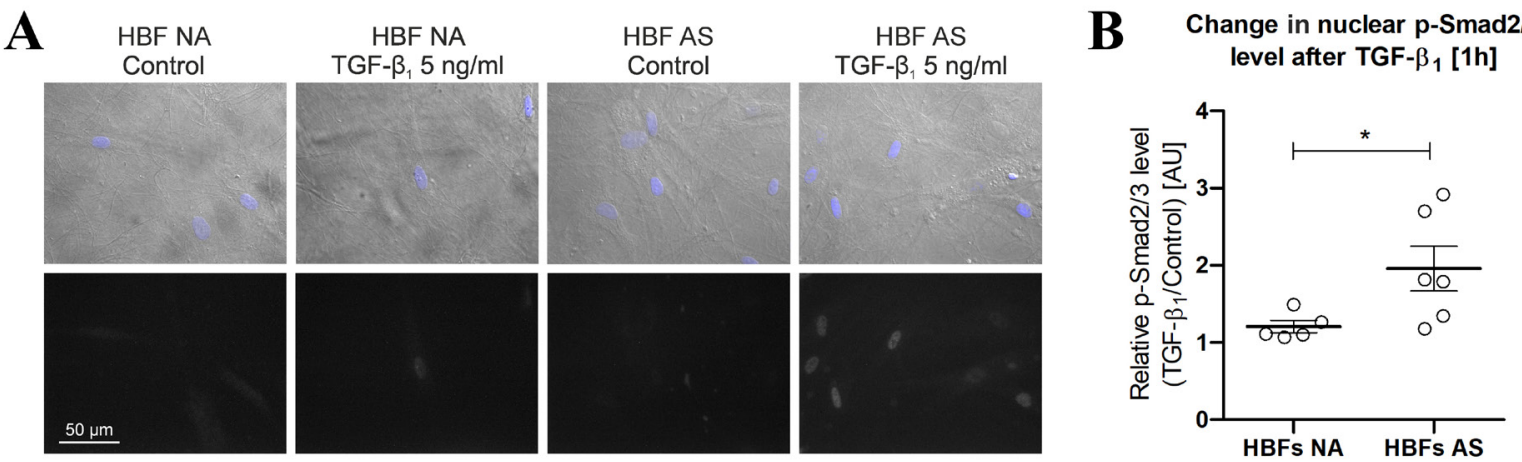

Figure 5. Increase of nuclear $\mathrm{p}-\mathrm{Smad} 2 / 3$ level after TGF- $\beta_{1}$ treatment is significantly more prominent in case of HBFs derived from patients diagnosed with asthma.

(A) Images of representative AS and NA HBFs obtained with DIC merged with blue fluorescence of cell nuclei (Hoechst). Lower set shows signal from $\mathrm{p}$-Smad2/3 antibody conjugated with AlexaFluor-647. (B) Graph presenting relative level of nuclear p-Smad2/3 as a ratio of cells treated with TGF- $\beta_{1}$ for 1 hour to those grown under control conditions. Fluorescence of $p$-Smad2/3 specific antibody was normalized to fluorescence of the nuclear stain. Cells were cultivated as described above (serum starved for 48 hours in collagen gel of $1.5 \mathrm{mg} /$ $\mathrm{ml}$ ). $\mathrm{n}=5-6$ (NA and AS HBFs, respectively). Data represent the mean \pm S.E.M; ${ }^{*} p<0.05$; Student's $t$-test. 
et al., 2018). Most studies on FMT mechanisms are conducted in '2D' cell models, but they do not give a full cross-section of changes occurring in the diseased tissue. It has been proven that the tissue microenvironment and interactions of the connective tissue cells with extracellular matrix can have a key impact on FMT (Hinz, 2010; Klingberg et al., 2013; Kollmannsberger et al., 2018). Therefore, our experiments with standard in vitro culture in '2D' do not fully reflect the conditions in the tissue. Forces generated by the plastic on which the cells are growing are in no way comparable to those prevailing in the tissue ( $\mathrm{mPa} v$ s $\mathrm{kPa}$ ) (Balestrini et al., 2012). Hence, many signalling pathways can work differently, promoting FMT on a solid substrate (Huang et al., 2012).

While the $3 \mathrm{D}$ in vitro models can reflect in vivo conditions much more reliably than a simple monolayer cell culture, there were plenty of different approaches to obtain them in the past. They differ both in terms of the used substratum and the way of preparation (Edmondson et al., 2014). Type I collagen, as the most abundant component of extracellular matrix (ECM), is the first choice when fibrous connective tissue models are taken into consideration. Alternatively, fibrin gels, Matrigel or synthetic polyacrylamide substratum could be used (Han et al., 2004; Beningo et al., 2004; Serban et al., 2008), however, it was confirmed in the past that fibroblasts can remodel and align initially random collagen fibres, providing an increase in such model's reliability (Grinnell \& Lamke, 1984). The 3D in vitro model exploited in this paper was based on HBFs embedded in the collagen matrix. In this model, cells are uniformly mixed with the surrounding matrix directly before its polymerization (Rhee, 2009). We are aware that both, the abundance of collagen fibres and overall stiffness of collagen gel are much lower than in the reflected tissue, but such a simplified model is sufficient to provide cell morphology resembling the one known from in vivo conditions (Brown, 2013). Primarily, it prevents cells from contact with an extremely rigid substratum usually used for the '2D' in vitro conditions. It is also superior to seeding cells onto the surface of a collagen gel, where they can aggregate or even spread as on a rigid surface (da Rocha-Azevedo et al., 2013). Moreover, such conditions cannot be considered $3 \mathrm{D}$ as cells have contact with only one flat surface, while dorsal sides of cells are just bathed with the culture medium. It needs to be mentioned that in our 3D model the collagen gel remained attached to the chamber walls throughout the course of the experiment unless it was not contracted by cells when seeded at a sufficiently high density $\left(1.5 \times 10^{4} /\right.$ well $)$. Alternatively, the gel can be detached shortly after polymerization, which influences cell morphology, proliferation and overall cell signalling. The attached gel provides a significantly higher tension for cells than floating, and at least partially better mimicking native conditions (Kanta, 2015). In order to better mimic a tissue structure, such a collagen gel could be additionally fluid depleted and densified or solidified by crosslinking, but it significantly complicates the procedure or requires application of sophisticated and expensive research equipment (Brown, 2013). Morphology of the collagen embedded fibroblasts can be diverse, and it is often described as dendritic, stellate, spindle shaped, bipolar or rounded in some cases. Very often it is related to concentration of the gel, or conditions during polymerization. The collagen concentration that we examined was partially based on the literature where it is ranging from approximately 0.5 to 5 $\mathrm{mg} / \mathrm{ml}$ for fibroblastic cells (Adachi et al., 1998; Sawhney \& Howard, 2002; Brown, 2013; Boraldi et al., 2016). It should be noted here that according to some research, the real collagen concentration in such setting can be non-homogenous and increases even by two-folds in proximity to the bottom because of the influence of gravity during the polymerization process (Brown et al., 2005). Although it is still far from the collagen level in the modelled tissue (which can be even two orders of magnitude higher), cells are effectively prevented from interaction with a rigid substratum, which is additionally provided by a cell-free collagen layer polymerized in the well before the proper cell-containing collagen is introduced (Artym \& Matsumoto, 2010; Brown, 2013). We demonstrated that the HBFs morphology varies visibly with the increase of the collagen concentration in terms of the quantity of protrusions, general morphology and size. Additionally, during a short-term observation, we could register a dynamic behaviour of cells with plenty of extended protrusions, as well as partial translocation between focal planes. It was presented in the past that fibroblasts of various origin dynamically migrate in the collagen matrices of such order of concentration (1-4 $\mathrm{mg} / \mathrm{ml}$ ), while at much higher concentrations (40 mg/ $\mathrm{ml}$ ), the process was observed in the timescale of days or weeks, and required activity of proteolytic enzymes (Helary et al., 2005; Grinnell \& Petroll, 2010; MironMendoza et al., 2010). It is also known that together with the increase in collagen concentration, there is a proportional drop in the pore size rather than the change in the thickness of fibres (Miron-Mendoza et al., 2010). This could explain the less extended morphology of HBFs at the highest examined concentrations. On the other hand, human foreskin fibroblasts presented dendritic morphology even in at $4.0 \mathrm{mg} / \mathrm{ml}$ collagen concentrations (Miron-Mendoza et al., 2010). Moreover, confinement inside the fibrous connective tissue is also much higher. The cell morphology observed here can be compared to other similar experiments. For example, a long term culture (4-weeks) of human skin fibroblasts showed stellate morphology in the floating gel, while cells were bipolar in the attached gel (Nakagawa et al., 1989). Spindle shaped morphology was observed in case of human corneal fibroblasts embedded in the attached collagen gel of 2.0 $\mathrm{mg} / \mathrm{ml}$ (Sugioka et al., 2017), whereas the transfer of rat liver myofibroblasts from a solid substrate to collagen gel resulted in change in the cell morphology from large and flatten, into thin with long extensions (Peterova et al., 2016). In our experiments, all types of morphology were visible, and our observations can suggest that due to their heterogeneity, $\mathrm{HBF}$ populations slightly differ from fibroblastic cells of other origin growing in such a type of the 3D model. We also showed, for the first time, a profound difference in $\alpha$-SMA mRNA expression between TGF- $\beta$-treated HBFs from AS and NA group cultured in $3 \mathrm{D}$ collagen gel, even though the changes of their morphology in comparison to unstimulated cells were not observed. However, this effect was less pronounced in 3D collagen gel in comparison to our earlier results with the 2D model (Michalik et al., 2009, 2011, Paw et al. 2017, Wnuk et al., 2020). It was previously demonstrated that the compliance of collagen gels regulated TGF- $\beta$-induction of $\alpha$-SMA expression in human gingival fibroblasts (Arora et al., 1999). Moreover, a less pronounced induction of FMT was also described in human vocal fold fibroblasts cultivated under the 3D conditions in comparison to standard 2D cultures (Chen et al., 2012).

It is well known that fibroblasts differentiate into myofibroblasts more strongly under the influence of the substrate stiffness due to mechano-transduction (Hinz, 
2010; Huang et al., 2012). Furthermore, TGF- $\beta_{1}$ enhances the FMT process, which translates into the reorganization of the extracellular matrix. Although no significant changes in the HBFs' morphology were observed in the 3D model, we showed both, under the control conditions and after TGF- $\beta_{1}$ stimulation, that in the collagen shrinkage test fibroblasts derived from asthmatics shrink the collagen in which they grow considerably more than their non-asthmatic counterparts. This may be due to the increased predisposition of these cells to FMT, which was demonstrated by the examined FMT markers in our model: $\alpha$-SMA and Sm22. Similar observations have been made in the airway smooth muscle cells from asthmatics and non-asthmatics (Matsumoto et al., 2007). The significant positive correlation between the contraction of collagen gels after TGF- $\beta_{1}$ treatment with $\alpha$-SMA expression was observed in the bovine corneal fibroblasts (Kurosaka et al., 1998), and human skin fibroblasts from palmar aponeurosis from patients with the Dupuytren's disease (Tomasek \& Rayan, 1995; Vaughan et al., 2000), and human foetal lung fibroblasts (Kobayashi et al., 2005).

Moreover, fibroblasts from asthmatics, as in the '2D' model, produce more extracellular matrix proteins (COL1, FN1) when compared to their non-asthmatic counterparts. Similarly to the '2D' model (Paw et al., 2017, 2018; Wnuk et al., 2020), this is due to the increased activation of the TGF- $\beta / \mathrm{Smad} 2 / 3$ pathway, which is a canonical pathway through which FMT induction occurs. All of the processes described above are less pronounced than in the '2D' model, which may be related to the insufficiently rigid substratum, but the differences between cells from asthmatics and non-asthmatics are evident. To conclude, the results of our study undoubtedly demonstrate that fibroblasts from asthmatics have unique intrinsic features which predispose them to increased FMT under the influence of TGF- $\beta_{1}$, regardless of the culture conditions.

\section{Acknowledgements}

The authors would like to express their gratitude to Professor Grażyna Bochenek for her crucial help in the recruitment of patients, Professor Krzysztof Sładek for obtaining the bronchial biopsies and Sylwia Bobis-Wozowicz, Ph.D. for primer design.

\section{Conflicts of Interest}

The authors confirm that there are no conflicts of interest.

\section{REFERENCES}

Adachi Y, Mio T, Takigawa K, Striz I, Romberger DJ., Spurzem JR, Rennard SI (1998) Fibronectin production by cultured human lung fibroblasts in three-dimensional collagen gel culture. Vitr. Cell. Dev. Biol. 34: 203-210

Arora PD, Narani N, McCulloch CA (1999) The compliance of collagen gels regulates transforming growth factor-beta induction of alpha-smooth muscle actin in fibroblasts. Am. J. Pathol. 154: 871-882. https://doi.org/10.1016/S0002-9440(10)65334-5

Artym VV, Matsumoto K (2010) Imaging cells in three-dimensional collagen matrix. Curr. Protoc. Cell Biol. 48: 10.18.1-10.18.20. https:// doi.org/10.1002/0471143030.cb1018s48

Balestrini JL, Chaudhry S, Sarrazy V, Koehler A, Hinz B (2012) The mechanical memory of lung myofibroblasts. Integr. Biol. 4: 410. https://doi.org/10.1039/c2ib00149g

Beningo KA, Dembo M, Wang Y (2004) Responses of fibroblasts to anchorage of dorsal extracellular matrix receptors. Proc. Natl. Acad. Sci. U. S. A. 101: 18024-18029. https://doi.org/10.1073/ pnas. 0405747102
Boraldi F, Bartolomeo A, Annovi G, Debret R, Quaglino D (2016) Magnesium modifies the structural features of enzymatically mineralized collagen gels affecting the retraction capabilities of human dermal fibroblasts embedded within this 3D system. Materials (Basel). 9: 477. https://doi.org/10.3390/ma9060477

Brown RA, Wiseman M, Chuo C-B, Cheema U, Nazhat SN (2005) Ultrarapid engineering of biomimetic materials and tissues: fabrication of nano- and microstructures by plastic compression. Adv. Funct. Mater. 15: 1762-1770. https://doi.org/10.1002/adfm.200500042

Brown RA (2013) In the beginning there were soft collagen-cell gels: towards better 3D connective tissue models? Exp. Cell Res. 319: 2460-2469. https://doi.org/10.1016/j.yexcr.2013.07.001

Chen X, Thibeault SL (2012) Response of fibroblasts to transforming growth factor- $\beta 1$ on two-dimensional and in three-dimensional hyaluronan hydrogels. Tissue Eng. Part A 18: 2528-2538. https://doi. org/10.1089/ten.tea.2012.0094

da Rocha-Azevedo B, Ho C-H, Grinnell F (2013) Fibroblast cluster formation on 3D collagen matrices requires cell contraction dependent fibronectin matrix organization. Exp. Cell Res. 319: 546-555. https://doi.org/10.1016/j.yexcr.2012.10.005

Di Modugno F, Colosi C, Trono P, Antonacci G, Ruocco G, Nisticò P (2019) 3D models in the new era of immune oncology: focus on $\mathrm{T}$ cells, CAF and ECM. J. Exp. Clin. Cancer Res. 38: 117. https:// doi.org/10.1186/s13046-019-1086-2

Edmondson R, Broglie JJ, Adcock AF, Yang L (2014) Three-dimensional cell culture systems and their applications in drug discovery and cell-based biosensors. Assay Drug Dev. Technol. 12: 207-218. https://doi.org/10.1089/adt.2014.573

Gabbiani G (2003) The myofibroblast in wound healing and fibrocontractive diseases. J. Pathol. 200: 500-503. https://doi.org/10.1002/ path.1427

Grinnell F, Lamke CR (1984) Reorganization of hydrated collagen lattices by human skin fibroblasts. J. Cell Sci. 66: 51-63

Grinnell F, Petroll WM (2010) Cell motility and mechanics in three-dimensional collagen matrices. Annu. Rev. Cell Dev. Biol. 26: 335-361. https://doi.org/10.1146/annurev.cellbio.042308.113318

Han Y-P, Zhou L, Wang J, Xiong S, Garner WL, French SW, Tsukamoto H (2004) Essential role of matrix metalloproteinases in interleukin-1-induced myofibroblastic activation of hepatic stellate cell in collagen. J. Biol. Chem. 279: 4820-4828. https://doi.org/10.1074/jbc. M310999200

Helary C, Foucault-Bertaud A, Godeau G, Coulomb B, Guille MMG (2005) Fibroblast populated dense collagen matrices: cell migration, cell density and metalloproteinases expression. Biomaterials 26: 15331543. https://doi.org/10.1016/j.biomaterials.2004.05.016

Hinz B (2010) The myofibroblast: paradigm for a mechanically active cell. J. Biomech. 43: 146-155. https://doi.org/10.1016/j.jbiomech.2009.09.020

Huang X, Yang N, Fiore VF, Barker TH, Sun Y, Morris SW, Ding Q, Thannickal VJ, Zhou Y (2012) Matrix stiffness-induced myofibroblast differentiation is mediated by intrinsic mechanotransduction. Am. J. Respir. Cell Mol. Biol. 47: 340-348. https://doi.org/10.1165/ rcmb.2012-0050OC

Kanta J (2015) Collagen matrix as a tool in studying fibroblastic cell behavior. Cell Adhes. Migr. 9: 308-316

Klingberg F, Hinz B, White ES (2013) The myofibroblast matrix: implications for tissue repair and fibrosis. J. Pathol. 229: 298-309. https://doi.org/10.1002/path.4104

Kobayashi T, Liu X, Kim HJ, Kohyama T, Wen FQ, Abe S, Fang Q, Zhu YK, Spurzem JR, Bitterman P, Rennard SI (2005) TGF- $\beta 1$ and serum both stimulate contraction but differentially affect apoptosis in 3D collagen gels. Respir. Res. 6: 1-12. https://doi. org/10.1186/1465-9921-6-141

Kofron CM, Mende U (2017) In vitro models of the cardiac microenvironment to study myocyte and non-myocyte crosstalk: bioinspired approaches beyond the polystyrene dish. J. Physiol. 595: 3891-3905. https://doi.org/10.1113/JP273100

Kollmannsberger P, Bidan CM, Dunlop JWC, Fratzl P, Vogel V (2018) Tensile forces drive a reversible fibroblast-to-myofibroblast transition during tissue growth in engineered clefts. Sci. Adv. 4. https:// doi.org/10.1126/sciadv.aao4881

Kural MH, Billiar KL (2013) Regulating tension in three-dimensional culture environments. Exp. Cell Res. 319: 2447-2459. https://doi. $\operatorname{org} / 10.1016 /$ j.yexcr.2013.06.019

Kurosaka H, Kurosaka D, Kato K, Mashima Y, Tanaka Y (1998) Transforming growth factor- $\beta 1$ promotes contraction of collagen gel by bovine corneal fibroblasts through differentiation of myofibroblasts. Investig. Ophthalmol. Vis. Sci. 39: 699-704

Matsumoto H, Moir LM, Oliver BGG, Burgess JK, Roth M, Black JL, McParland BE (2007) Comparison of gel contraction mediated by airway smooth muscle cells from patients with and without asthma. Thorax 62: 848-854. https://doi.org/10.1136/thx.2006.070474

Meran S, Steadman R (2011) Fibroblasts and myofibroblasts in renal fibrosis. Int. J. Exp. Pathol. 92: 158-167. https://doi.org/10.1111/ j.1365-2613.2011.00764.x 
Michalik M, Pierzchalska M, Legutko A, Ura M, Ostaszewska A, Soja J, Sanak M (2009) Asthmatic bronchial fibroblasts demonstrate enhanced potential to differentiate into myofibroblasts in culture. Med. Sci. Monit. 15: 194-201

Michalik M, Pierzchalska M, Włodarczyk A, Wójcik KA, Czyż J, Sanak M, Madeja Z (2011) Transition of asthmatic bronchial fibroblasts to myofibroblasts is inhibited by cell-cell contacts. Respir. Med. 105: 1467-1475. https://doi.org/10.1016/j.rmed.2011.04.009

Michalik M, Soczek E, Kosińska M, Rak M, Wójcik KA, Lasota S, Pierzchalska M, Czyż J, Madeja Z (2013) Lovastatin-induced decrease of intracellular cholesterol level attenuates fibroblast-to-myofibroblast transition in bronchial fibroblasts derived from asthmatic patients. Eur. J. Pharmacol. 704: 23-32. https://doi.org/10.1016/j. ejphar.2013.02.023

Michalik M, Wójcik-Pszczoła K, Paw M, Wnuk D, Koczurkiewicz P, Sanak M, Pękala E, Madeja Z (2018) Fibroblast-to-myofibroblast transition in bronchial asthma. Cell. Mol. Life Sci. 75: 3943-3961. https://doi.org/10.1007/s00018-018-2899-4

Michalik M, Wójcik KA, Jakieła B, Szpak K, Pierzchalska M, Sanak M, Madeja Z, Czyż J (2012) Lithium Attenuates TGF- $\beta$ (1)-Induced Fibroblasts to Myofibroblasts Transition in Bronchial Fibroblasts Derived from Asthmatic Patients. J. Allergy 2012: 206109. https:// doi.org/10.1155/2012/206109

Miron-Mendoza M, Seemann J, Grinnell F (2010) The differential regulation of cell motile activity through matrix stiffness and porosity in three dimensional collagen matrices. Biomaterials 31: 6425-6435. https://doi.org/10.1016/j.biomaterials.2010.04.064

Nakagawa S, Pawelek P, Grinnell F (1989) Long-term culture of fibroblasts in contracted collagen gels: effects on cell growth and biosynthetic activity. J. Invest. Dermatol. 93: 792-798. https://doi. org/10.1111/1523-1747.ep12284425

Omori K, Hattori N, Senoo T, Takavama Y, Masuda T, Nakashima T, Iwamoto H, Fujitaka K, Hamada H, Kohno N (2016) Inhibition of plasminogen activator inhibitor-1 attenuates transforming growth factor- $\beta$-dependent epithelial mesenchymal transition and differentiation of fibroblasts to myofibroblasts. PLoS One 11: e0148969. https://doi.org/10.1371/journal.pone.0148969

Paw M, Borek I, Wnuk D, Ryszawy D, Piwowarczyk K, Kmiotek K, Wojcik-Pszczoła KA, Pierzchalska M, Madeja Z, Sanak M, Błyszczuk P, Michalik M, Czyż J (2017) Connexin43 controls the myofibroblastic differentiation of bronchial fibroblasts from patients with asthma. Am. J. Respir. Cell Mol. Biol. 57: 100-110. https://doi. org/10.1165/rcmb.2015-0255OC

Paw M, Wnuk D, Kadziołka D, Sęk A, Lasota S, Czyż J, Madeja Z, Michalik M (2018) Fenofibrate reduces the asthma-related fibroblast-to-myofibroblast transition by $\mathrm{TGF}-\mathrm{B} / \mathrm{S} \operatorname{mad} 2 / 3$ signaling attenuation and connexin 43-dependent phenotype destabilization. Int. J. Mol. Sci. 19. https://doi.org/10.3390/ijms19092571

Peterova E, Mrkvicová A, Podmolíková L, Rezáčová M, Kanta J (2016) The Role of cytokines tgf-betal and fgf- 1 in the expression of characteristic markers of rat liver myofibroblasts cultured in three-dimensional collagen gel. Physiol. Res. 65: 66-672. https://doi. org/10.33549/physiolres.933092

Petrie RJ, Yamada KM (2015) Fibroblasts lead the way: a unified view of three-dimensional cell motility. Trends Cell Biol. 25: 666-674. https://doi.org/10.1016/j.tcb.2015.07.013.Fibroblasts

Rhee S (2009) Fibroblasts in three dimensional matrices: cell migration and matrix remodeling. Exp. Mol. Med. 41: 858-865. https://doi. org/10.3858/emm.2009.41.12.096

Sarna M, Wójcik KA, Hermanowicz P, Wnuk D, Burda K, Sanak M, Czyż J, Michalik M (2015) Undifferentiated bronchial fibroblasts derived from asthmatic patients display higher elastic modulus than their non-asthmatic counterparts. PLOS One 10. https://doi. org/10.1371/journal.pone.0116840

Sarrazy V, Billet F, Micallef L, Coulomb B, Desmoulière A (2011) Mechanisms of pathological scarring: role of myofibroblasts and current developments. Wound Repair Regen. 19 (Suppl 1): s10-s5. https://doi.org/10.1111/j.1524-475X.2011.00708.x

Sawhney RK, Howard J (2002) Slow local movements of collagen fibers by fibroblasts drive the rapid global self-organization of collagen gels. J. Cell Biol. 157: 1083-1091. https://doi.org/10.1083/ jcb.200203069

Schindelin J, Arganda-Carreras I, Frise E, Kaynig V, Longair M, Pietzsch T, Preibisch S, Rueden C, Saalfeld S, Schmid B, Tinevez J-Y, White DJ, Hartenstein V, Eliceiri K, Tomancak P, Cardona A (2012) Fiji: an open-source platform for biological-image analysis. Nat. Methods 9: 676-682. https://doi.org/10.1038/nmeth.2019

Serban MA, Liu Y, Prestwich GD (2008) Effects of extracellular matrix analogues on primary human fibroblast behavior. Acta Biomater. 4: 67-75. https://doi.org/10.1016/j.actbio.2007.09.006

Sugioka K, Kodama-Takahashi A, Yoshida K, Aomatsu K, Okada K, Nishida T, Shimomura Y (2017) Extracellular collagen promotes interleukin-1 $\beta$-induced urokinase-type plasminogen activator production by human corneal fibroblasts. Investig. Ophthalmol. Vis. Sci. 58: 1487-1498. https://doi.org/10.1167/iovs.16-20685

Tomasek J, Ravan GM (1995) Correlation of $\alpha$-smooth muscle actin expression and contraction in Dupuytren's disease fibroblasts. J. Hand Surg. Am. 20: 450-455. https://doi.org/10.1016/S03635023(05)80105-4

Vaughan MB, Howard EW, Tomasek JJ (2000) Transforming growth factor- $\beta 1$ promotes the morphological and functional differentiation of the myofibroblast. Exp. Cell Res. 257: 180-189. https://doi. org/10.1006/excr.2000.4869

Westergren-Thorsson G, Larsen K, Nihlberg K, Andersson-Sjöland A, Hallgren O, Marko-Varga G, Bjermer L (2010) Pathological airway remodelling in inflammation. Clin. Respir. J. 4: 1-8. https://doi. org/10.1111/j.1752-699X.2010.00190.x

Wnuk D, Paw M, Ryczek K, Bochenek G, Sładek K, Madeja Z, Michalik M (2020) Enhanced asthma-related fibroblast to myofibroblast transition is the result of profibrotic TGF- $\beta / \mathrm{Smad} 2 / 3$ pathway intensification and antifibrotic TGF- $\beta / \mathrm{Smad} 1 / 5 /(8) 9$ pathway impairment Sci. Rep. 10: 16492. https://doi.org/10.1038/s41598-02073473-7

Wójcik-Pszczoła K, Hińcza K, Wnuk D, Kądziołka D, Koczurkiewicz P, Sanak M, Madeja Z, Pękala E, Michalik M (2016) Pentoxifylline and its active metabolite lisofylline attenuate transforming growth factor $\beta 1$-induced asthmatic bronchial fibroblast-to-myofibroblast transition. Acta Biochim. Pol. 63: 437-442. https://doi.org/10.18388/ abp.2016_1357

Wójcik-Pszczoła K, Jakieła B, Plutecka H, Koczurkiewicz P, Madeja Z, Michalik M, Sanak M (2018) Connective tissue growth factor regulates transition of primary bronchial fibroblasts to myofibroblasts in asthmatic subjects. Cytokine 102: 187-190. https://doi. org/10.1016/j.cyto.2017.09.002

Wójcik K, Koczurkiewicz P, Michalik M, Sanak M (2012) Transforming growth factor- $\beta 1$-induced expression of connective tissue growth factor is enhanced in bronchial fibroblasts derived from asthmatic patients. Polish Arch. Intern. Med. 122: 326-332. https:// doi.org/10.20452/pamw.1343 